This item was submitted to Loughborough's Research Repository by the author.

Items in Figshare are protected by copyright, with all rights reserved, unless otherwise indicated.

\title{
Infant deaths from congenital anomalies: novel use of Child Death Overview Panel data
}

PLEASE CITE THE PUBLISHED VERSION

http://dx.doi.org/10.1136/archdischild-2017-314256

PUBLISHER

BMJ Publishing Group

VERSION

AM (Accepted Manuscript)

\section{PUBLISHER STATEMENT}

This work is made available according to the conditions of the Creative Commons Attribution-NonCommercialNoDerivatives 4.0 International (CC BY-NC-ND 4.0) licence. Full details of this licence are available at: https://creativecommons.org/licenses/by-nc-nd/4.0/

\section{LICENCE}

CC BY-NC-ND 4.0

\section{REPOSITORY RECORD}

Firth, Catriona, Emily Petherick, and Sam J. Oddie. 2019. "Infant Deaths from Congenital Anomalies: Novel Use of Child Death Overview Panel Data". figshare. https://hdl.handle.net/2134/28411. 
Infant deaths from congenital anomalies: novel use of CDOP data

\section{Corresponding Author:}

Dr Catriona Firth

Neonatal Unit, Bradford Royal Infirmary, Duckworth Lane, Bradford. BD9 6RJ.

Catriona-elizabeth.firth@nhs.net

Tel: 07789952921

Fax: 01274282259

Co-Authors:

Dr Emily Petherick

Born in Bradford, Bradford Institute for Health Research, Bradford, UK.

School of Sport, Exercise and Health Sciences, Loughborough University, Loughborough, UK.

Dr Sam J Oddie

Centre for reviews and dissemination, University of York, York, UK.

Neonatal Unit, Bradford Royal Infirmary, Bradford, UK

Keywords:

Infant mortality, congenital anomaly, ethnicity.

Word Count: 


\section{Abstract}

Objective: We aimed to assess Child Death Overview Panel (CDOP) data validity, and cause of death classification, by comparison with information from a local birth cohort study (Born in Bradford, BiB), and another cause of death coding system (Causes of death and associated conditions - CODAC). We then aimed to use CDOP data to calculate ethnic specific IMRs, and compare characteristics of infants who died of congenital anomalies (CA) to those who died from other causes (non-CA).

Design: Retrospective cohort study.

Setting: Bradford Metropolitan District.

Patients: All infant deaths, 2008 to 2013.

Main outcome measures: Infant mortality rates from CA and non-CA causes.

Results: 315 infant deaths were included, 56 of whom were BiB recruits. Agreement between $\mathrm{CDOP}$ and $\mathrm{BiB}$ was moderate to perfect for all characteristics except ethnicity, which showed weak agreement (kappa=0.58). The same deaths $(27 / 56)$ were classified as CA by CDOP and CODAC. IMRs (per 1000 live births, 2009-2013) were highest in Pakistani infants (all causes 9.8, CA cause 5.5) compared with White British (all causes 4.3, CA cause 1.3), and Other infants (all causes 5.1, CA cause 1.4). In multivariate analysis, infants who died of CA cause were more likely to have been born at term (OR 3.18) and to consanguineous parents (OR 3.28) than infants who died of non-CA cause. 
Conclusions: Excess Pakistani mortality appears to be partly explained by an excess of deaths from CA, which in this population appears associated with a greater prevalence of consanguinity. 


\section{Introduction}

Infant mortality rates (IMRs) in England and Wales vary among different ethnic groups. In 2013, infants of Pakistani ethnicity had the highest IMR at 6.7 per 1000 live births, compared with an overall rate of 3.8. ${ }^{1}$ Between 2008 and 2013, IMRs of Pakistani, Black Caribbean and Black African infants have consistently been amongst the highest. ${ }^{1}$

Causes of infant death also vary by ethnicity. The Office for National Statistics (ONS) combines ethnic groups to report cause of death information. In 2013, for the combined Asian group, the most common cause of death was congenital anomalies (41\%). In all other groups, the most common causes of death were immaturity related conditions (accounting for $42-53 \%$ of deaths). ${ }^{1}$ Again, this has been a consistent over time. ${ }^{1}$

Both the variation in IMR in different ethnicities, and the difference in causes of death were highlighted by the National Perinatal Epidemiology Unit as important areas for future research. $^{23}$

Bradford is an ethnically diverse city in the north of England with high levels of deprivation. In recent years, following a multidisciplinary Infant Mortality Commission and implementation programme, infant mortality has fallen. Despite this, Bradford's IMR remains above national average. The 3-year rolling average in 2010-2012 was 7.0 per 1000 live births, compared with 4.3 in the rest of England and Wales. ${ }^{4}$

The prevalence of congenital anomalies and childhood disability in Bradford is recognised as being amongst the highest in the UK. ${ }^{6-8}$ A recent analysis from Born in Bradford (BiB - a large multi-ethnic birth cohort study) found the rate of congenital anomalies in Bradford to be almost double that of the national average, with a higher risk in mothers of Pakistani origin 
compared with white British origin. ${ }^{9}$ Consanguinity was identified as a major risk factor, even after adjustment for deprivation. ${ }^{9}$ Increased maternal age is a well associated risk for congenital anomaly. In the BiB study, only white British mothers older than 34 years had an increased risk of congenital anomaly. ${ }^{9}$

In 2008, Child Death Overview Panels (CDOPs) were introduced as part of the Government's Working Together to Safeguard Children Framework. ${ }^{10}$ All infant and child deaths have since been systematically reviewed and analysed by multi-professional panels in order to identify modifiable factors, with an aim to prevent future deaths. Panels decide on the cause of death in each case, based on a standard hierarchical classification schema. Precise practices and information obtained vary according to local policy.

We aimed to assess the validity of information collected by Bradford district's CDOP by comparing it to information obtained by BiB. Our second aim was to calculate ethnic specific IMRs, and to compare characteristics of infants who died with congenital anomalies to those who died from other causes.

\section{Methods}

We performed a retrospective cohort analysis of all infant deaths in Bradford district between 2008 and 2013. We extracted data on each infant from their anonymised CDOP file.

We identified all infant deaths in the BiB cohort and linked them to their CDOP identifier via their NHS number. Full BiB methods have been published previously. ${ }^{11}$ Information was collected from mothers by interviewer-administered questionnaire during pregnancy, as 
well as from routine maternity records data. We calculated Kappa values to describe agreement between case characteristics, collected by both data sources. ${ }^{12}$

We compared cause of death as attributed by the CDOP to that obtained using a separate classification of infant death. Two clinical investigators (CF and SO) independently processed CDOP cause of death information using CODAC (Causes of Death and Associated Conditions)

- Version 2 (available at http://www.biomedcentral.com/content.supplementary/14712393-9-22-51.xls). ${ }^{13}$ Each investigator was familiar with the coding "rules" and was blind to CDOP's classification at the time of coding. Discrepancies were discussed and resolved. We compared the proportion of deaths classified as Congenital Anomaly cause by both systems.

We obtained live birth denominator data from hospitals serving the Bradford District (Bradford Royal Infirmary and Airedale General Hospital) maternity systems.

Statistical Analysis

We calculated standard infant mortality rates (number of deaths / number of live births, and reported per 1000 births). We calculated rates separately for the three main ethnic groups (Pakistani, white British and Other), as well as all three groups combined. We used Excel and an online tool (http:statpages.info/confint.xls) to calculate IMRs and their 95\% binomial confidence interval separately for deaths CDOP attributed to chromosomal, genetic or congenital anomaly cause (hereafter referred to as congenital anomaly (CA) deaths), all other causes (hereafter referred to as non-congenital anomaly (non-CA) deaths), and both groups combined (ie. all causes).

We conducted logistic regression to calculate univariate and multivariate odds ratios (ORs) and $95 \%$ confidence intervals for the occurrence of CA death when compared to non-CA 
causes of death. Multivariable models were mutually adjusted for infant characteristics recorded by CDOP including age at death, gestation, prematurity, gender, birth weight, deprivation quintile, parental consanguinity, maternal age, smoking in pregnancy and maternal illness. Deprivation quintile was calculated using the Index of Multiple Deprivation (IMD) 2010 tool (available at http://tools.npeu.ox.ac.uk/imd/), according to infant's postcode at the time of death.

All other statistical analyses were conducted using Stata 14SE. ${ }^{14}$

Ethical approval

The study was initially performed as part of an MSc in Child Health undertaken by CF. Ethics approval was not deemed necessary. CF held an Honorary Contract with the host organisation and the CDOP authorised access to the data. We contacted the Research Ethics Committee (REC) about our intention to publish aspects of the research. They confirmed that as the data analysed was anonymised and collected for other purposes, formal REC approval was not required.

\section{$\underline{\text { Results }}$}

We identified 333 infant deaths occurring between 2008 and 2013 from Bradford district's CDOP, of which 315 were suitable for inclusion. 14 deaths in infants born at less than or equal to 22 weeks gestation had been reviewed but were excluded on the basis of gestation. A further three deaths in infants born to women not resident in the Bradford metropolitan district were excluded. 1 infant did not have an NHS number recorded and was also excluded. 
The median age at death was 10 days (range 0 to 355 days). 163 (52\%) were male and 152 (48\%) were female. Of the three main ethnic groups, 166 (53\%) were Pakistani, 96 (30\%) were white British, and 53 (17\%) were Other. "Chromosomal, genetic and congenital anomaly," and "neonatal/perinatal events" were the commonest causes of death, accounting for $140(44 \%)$ and $136(43 \%)$ of deaths respectively. 18 (5.7\%) of deaths were classified as due to infection, 9 (2.9\%) were sudden unexpected unexplained deaths. The remaining 12 infants died of other causes.

Validity of CDOP data:

56 infants reviewed by CDOP had been recruited to the BiB study and had died before reaching a year of age. For these 56 infants there was only weak agreement for ethnicity data obtained from the different sources (kappa $=0.58$, SE 0.10). Agreement was almost perfect, strong or moderate for all other characteristics. See Table 1.

We found no differences in the proportion of deaths attributed to congenital anomaly by the two coding systems, with the same $27 / 56$ (48\%) deaths being attributed to congenital anomaly by both the CDOP review panel and the CODAC coding system.

IMRs:

IMRs were not calculated for 2008 deaths. Numerator data was incomplete as CDOP started reviewing deaths in March of 2008.

IMRs were consistently higher in the Pakistani group. In this study, the Pakistani IMR across all 5 years from all causes was 9.8 per 1000 live births (compared with 4.3 in white British, 5.1 in Other). The infant mortality rate from congenital anomaly (CA IMR) was higher among 
Pakistani infants than other ethnic groups (5.4 Pakistani, 1.3 white British, 1.4 Other). See Table 2.

Comparison of CA and Non-CA deaths:

In multivariate analysis, infants who died of CA cause were more likely to be born at term (OR 3.18, 95\% $\mathrm{Cl} 1.34-7.54, \mathrm{p}=0.008$ ), and to be the product of consanguineous unions (OR $3.28,95 \% \mathrm{Cl} 1.48-7.29, \mathrm{p}=0.004)$ than infants who died of non-CA causes. In multivariate analysis we demonstrated no differences in ethnicity, age at death, birthweight, deprivation, gender, maternal age, maternal smoking in pregnancy or maternal illness between infants who died of CA cause and those who did not. See Tables 3 and 4.

\section{Discussion}

We have demonstrated that infant deaths from congenital anomaly in Bradford metropolitan district are three times more likely to have consanguineous parents than infants who die from non-congenital anomaly cause, but that there is no such association with ethnicity. Researcher derived and CDOP derived data about cases of infant death was substantially in agreement, albeit with poorer agreement about the classification of ethnicity. Cause of death recorded by the CDOP exactly matched researcher review of infant cause of death.

This is the first detailed analysis of infant mortality using CDOP data, collected routinely for all child deaths. Local analyses such as this are useful for recognising and understanding trends in infant mortality, particularly in areas such as Bradford where the IMR is higher than national average. 
Other strengths of our study include its population based nature, the six years of included data, that we were able to validate CDOP infant and family characteristics data against researcher collected information with predominantly good agreement, the use of area level measures of socioeconomic deprivation (meaning we had low levels of missingness), that we were able to validate the dichotomisation of cause of infant death as CA or non-CA against the well-recognised CODAC classification, and that the study population is enriched for important variables of interest such as low birthweight, ethnicity and consanguinity.

Limitations of our study include the possibility of reporting bias. Although unlikely, it is possible the CDOP recorded consanguinity status or ethnicity differently in cases of CA death, which could have biased our measures of association. While we have a measure of consanguinity, we have been unable to include any measure of endogamy in our multivariate analysis of the differences between CA and non-CA infant deaths. Information regarding endogamy is not routinely collected by CDOP and is more difficult to objectively measure. One third of Pakistani individuals in the BiB study were unaware of their own "biraderi" or patrilineage kinship group. ${ }^{9}$ Our measure of socioeconomic deprivation is area based rather than on individual family's experience, and may not fully encompass data on all aspects of deprivation experienced by families. ${ }^{15}$

Our estimates of ethnicity specific IMRs may be undermined by the fact some births (particularly from the smaller of the two maternity units) contributing to the denominator data for ethnicity specific birth numbers, may have been to families who are not resident in the metropolitan district. However, this use of a proxy denominator, and the possibility that births within the districts' two maternity units might not be fully representative of those births to the population of the district, do not seriously undermine our findings. The scale of 
the difference between ethnicity specific mortality rates (Pakistani 9.8 (95\% $\mathrm{Cl}$ 8.2-11.5); White British $4.3(95 \% \mathrm{Cl} 3.4-5.3))$ is such that the difference would remain significant even if our proxy measure of denominator overstated the Pakistani ethnicity births by as much as 25\%. We believe this to be implausible. Furthermore, this possible imprecision in description of underlying ethnicity specific birth rates does not undermine our main findings of the differences in infant characteristics between those infants who died of CA cause and those who died of non-CA cause.

The validation exercise we conducted between researcher-collected information and CDOP data showed only weak correlation between the two means of describing the ethnicity of a case. BiB researchers use self-reported maternal ethnicity as a proxy measure of infant ethnicity, while CDOP data aims to describe the baby's own ethnicity, which may explain some of the disparity. Difficulties in describing and recording infant ethnicity have been recognised as ethnicity is a self-defined concept, which makes its use in infants and other populations unable to self-report problematic. Previous studies have used infant ethnicity, ${ }^{16}$ maternal ethnicity, ${ }^{17}$ maternal country of birth, ${ }^{17}$ and composite variables, ${ }^{16}$ combining infant and maternal descriptors to try and overcome the limitation of the non-availability of self-report in this population.

Our finding that CA deaths occurred more in term babies is explained by the burden of prematurity in the of non-CA group.

The striking relationship in our study between CA death and consanguinity, in association with our clear finding of raised CA IMR in the Pakistani community (Pakistani CA IMR 5.5 per 1000 livebirths, White British CA IMR 1.3 per 1000 live births) suggests that the association between ethnicity and CA IM in this population is mediated by consanguinity. While we 
observed a strong association between Pakistani ethnicity and CA cause of death in univariate analysis, this was not observed in multivariate analysis where both ethnicity and consanguinity were considered in the same model.

These findings need to be dealt with sensitively to reflect the multi-factorial causal pathways underlying infant deaths, of which consanguinity is only one factor. Rather than alienating communities by discouraging consanguineous unions, which may have potential social and economic benefits, ${ }^{18}$ a family-centred approach to addressing genetic issues is needed. This has been recognised in many communities in which there are high levels of consanguinity. ${ }^{1920}$ Awareness of the benefits of pre-marital, pre-pregnancy and antenatal counselling is growing. ${ }^{19}$ Premarital screening is mandatory in certain middle-eastern countries with high levels of consanguinity, particularly for highly prevalent haemoglobin disorders (e.g. thalassaemia and sickle cell disease). Although screening is mandatory, decision making regarding the outcome is up to the individual couple involved. In one study, ninety percent of "incompatible" couples were reported to go on to marry, ${ }^{20}$ suggesting the approach of premarital testing alone is unlikely to be successful in reducing infant disease.

A great deal of work has been done in the Bradford area, including through the Every Baby Matters programme, ${ }^{21}$ conferences such as "Raising awareness of genetics among culturally diverse communities,"22 and more recently, the "Bradford Community Genetics Project." ${ }^{23}$ It is of note Sheridan et al found higher levels of maternal education to be associated with a lower risk of congenital anomaly. ${ }^{9}$ In the study by Bhopal et al mothers in consanguineous relationships had lower levels of education than their non-consanguineous counterparts, with the same patter seen in paternal education. ${ }^{18}$ 
Our findings re-iterate the need for antenatal counselling to routinely cover the risks of congenital anomaly associated with consanguinity, and to identify couples at particularly high risk (i.e. through taking of a thorough family history). There is continued need for culturally sensitive, clear and accessible information to be communicated both to couples and the wider community. Promoting discussion and improving awareness, particularly in those who are less well educated and potentially hardest to reach, may help further reduce infant mortality from CA cause. Identification of those at risk is important both from the point of view of the couple and future infants, but also at the health-commissioning level through enabling more targeted use of services and potentially further reducing infant mortality.

In contrast to previous studies, ${ }^{162425}$ we did not find an association between CA death and deprivation. It is of note two of these studies ${ }^{1624}$ used the Carstairs index (a postcode-based measure using census information of social class, car ownership, overcrowding and male unemployment) as their measure of deprivation, and the other ${ }^{25}$ used an earlier version of IMD. Levels of deprivation are generally high in Bradford, and the majority of infants who died of both CA and non-CA causes were from the fifth quintile ( $71 \%$ and $62 \%$ respectively). Our findings may be due to a lack of an association between CA death and deprivation in this group, the cohort being underpowered to illustrate this difference (particularly given the low variability in deprivation seen), or may reflect the use of an area-based deprivation measure. These findings of non-association with deprivation are consistent with earlier findings of congenital anomaly risk within the Born in Bradford study as a whole, where no additional excess risk was observed by deprivation status (measured either by IMD 2010 or by maternal educational level) of the population. ${ }^{9}$ 


\section{Conclusions}

Excess Pakistani mortality appears to be partly explained by an excess of deaths from congenital anomaly, which in this population appears to be associated with a much greater prevalence of consanguinity in this group. 
Table 1: Analysis of agreement in infant and family characteristic measures recorded by CDOP and BiB

\begin{tabular}{|l|l|l|}
\hline Characteristic & Kappa value (SE) & Level of agreement \\
\hline Ethnicity (BiB Mother vs. CDOP infant) & $0.58(0.10)$ & Weak \\
\hline Gender & $1.00(0.15)$ & Perfect \\
\hline Gestation & $1.00(0.10)$ & Perfect \\
\hline Birth Weight & $0.97(0.07)$ & Perfect \\
\hline Plurality & $1.00(0.15)$ & Perfect \\
\hline Consanguinity & $0.86(0.15)$ & Strong \\
\hline Deprivation & $0.90(0.15)$ & Strong \\
\hline Smoking & $0.75(0.15)$ & Moderate \\
\hline Smoking in Pregnancy & $0.93(0.15)$ & Perfect \\
\hline
\end{tabular}

Where kappa values of 0-0.2=no agreement, 0.21-0.39=minimal agreement, 0.40-0.59=weak agreement, 0.60-

$0.79=$ moderate agreement, $0.80 .0 .90=$ strong agreement and 0.90 and above=perfect agreement. ${ }^{12}$

Table 2: Ethnicity-specific IMRs (all cause, congenital anomaly cause and non-congenital anomaly cause), Bradford District 2009-2013

\begin{tabular}{|c|c|c|c|c|c|c|}
\hline Year & 2009 & 2010 & 2011 & 2012 & 2013 & All Years \\
\hline All Deaths: & Rate $(95 \% \mathrm{Cl})$ & Rate $(95 \% \mathrm{Cl})$ & Rate $(95 \% \mathrm{Cl})$ & Rate $(95 \% \mathrm{Cl})$ & Rate $(95 \% \mathrm{Cl})$ & Rate $(95 \% \mathrm{Cl})$ \\
\hline Pakistani & $11.2(7.8,15.6)$ & $13.1(9.3,18.0)$ & $9.9(6.6,14.2)$ & $6.7(4.0,10.5)$ & 7.6(4.7,11.6) & $9.8(8.2,11.5)$ \\
\hline White British & $4.7(2.8,7.4)$ & $4.4(2.6,7.0)$ & $3.4(1.8,5.7)$ & $5.3(3.2,8.1)$ & $3.6(1.9,6.1)$ & $4.3(3.4,5.3)$ \\
\hline Other & $6.0(2.9,11.0)$ & $8.1(4.4,13.6)$ & $5.2(2.4,9.9)$ & $4.0(1.6,8.3)$ & $2.3(0.6,5.9)$ & $5.1(3.7,6.9)$ \\
\hline All & $7.3(5.6,9.3)$ & $8.1(6.3,10.2)$ & $5.9(4.4,7.8)$ & $5.5(4.0,7.3)$ & $4.7(3.3,6.4)$ & $6.3(5.6,7.1)$ \\
\hline \multicolumn{7}{|l|}{ CA Deaths: } \\
\hline Pakistani & $5.8(3.4,9.1)$ & $7.9(5.0,11.9)$ & $6.0(3.5,9.6)$ & $3.9(1.9,7.0)$ & $3.6(1.7,6.7)$ & $5.5(4.3,6.8)$ \\
\hline White British & $0.5(0.1,1.8)$ & $1.0(0.3,2.5)$ & $1.0(0.3,2.6)$ & $2.1(0.9,4.1)$ & $1.9(0.8,4.0)$ & $1.3(0.8,1.9)$ \\
\hline Other & $0.6(0.0,3.3)$ & $2.9(0.9,6.7)$ & $1.2(0.1,4.2)$ & $2.3(0.6,5.9)$ & $0(0.0,2.1)$ & $1.4(0.7,2.4)$ \\
\hline All & $2.4(1.5,3.6)$ & $3.7(2.5,5.2)$ & $2.7(1.7,4.1)$ & $2.8(1.7,4.1)$ & $2.1(1.2,3.3)$ & $2.7(2.3,3.3)$ \\
\hline \multicolumn{7}{|l|}{$\begin{array}{l}\text { Non-CA } \\
\text { Deaths: }\end{array}$} \\
\hline Pakistani & $5.5(3.2,8.7)$ & $5.2(2.9,8.5)$ & $3.9(1.9,6.9)$ & $2.8(1.2,5.6)$ & $4.0(2.0,7.1)$ & $4.3(3.3,5.5)$ \\
\hline White British & $4.2(2.5,6.8)$ & $3.4(1.9,5.8)$ & $2.3(1.1,4.4)$ & $3.2(1.6,5.5)$ & $1.6(0.6,3.6)$ & $2.9(2.2,3.8)$ \\
\hline Other & $5.4(2.5,10.2)$ & $5.2(2.4,9.9)$ & $4.1(1.6,8.4)$ & $1.7(0.4,5.0)$ & $2.3(0.6,5.9)$ & $3.7(2.6,5.3)$ \\
\hline All & $4.9(3.5,6.6)$ & $4.4(3.1,6.0)$ & $3.2(2.1,4.7)$ & $2.8(1.7,4.1)$ & $2.6(1.6,3.9)$ & $3.6(3.0,4.2)$ \\
\hline
\end{tabular}

All rates crude $=$ no. deaths $/$ no. live births $\times 1000$. Binomial Confidence Interval. All IMR $=$ all cause, $C A$ IMR $=$ Congenital Anomaly cause, Non-CA IMR= non-congenital anomaly cause.

Table 3: Infant and family characteristics of infant deaths, Bradford district, 2008-2013

\begin{tabular}{|l|l|l|l|l|l|l|l|l|}
\hline \multicolumn{7}{|l}{ Congenital anomaly deaths } & \multicolumn{3}{l|}{ Non congenital anomaly deaths } \\
\hline & All & Pakistani & White & Other & All & Pakistani & White & Other \\
\hline Ethnicity & $140(44 \%)$ & $96(69 \%)$ & $28(20 \%)$ & $16(11 \%)$ & $175(56 \%)$ & $70(40 \%)$ & $68(39 \%)$ & $37(21 \%)$ \\
\hline Age at death & & & & & & & \\
\hline 0 & $31(22 \%)$ & $24(77 \%)$ & $4(13 \%)$ & $3(10 \%)$ & $41(23 \%)$ & $18(44 \%)$ & $18(44 \%)$ & $5(12 \%)$ \\
\hline $1-28$ days & $51(36 \%)$ & $30(59 \%)$ & $15(29 \%)$ & $6(12 \%)$ & $73(42 \%)$ & $19(26 \%)$ & $34(47 \%)$ & $20(27 \%)$ \\
\hline$>28$ days & $58(41 \%)$ & $42(72 \%)$ & $9(16 \%)$ & $7(12 \%)$ & $61(35 \%)$ & $33(54 \%)$ & $16(26 \%)$ & $12(20 \%)$ \\
\hline Gestation & & & & & & & & \\
\hline Preterm & $53(38 \%)$ & $35(66 \%)$ & $11(21 \%)$ & $7(13 \%)$ & $124(71 \%)$ & $51(41 \%)$ & $46(37 \%)$ & $27(22 \%)$ \\
\hline Term & $85(61 \%)$ & $59(69 \%)$ & $17(20 \%)$ & $9(11 \%)$ & $51(29 \%)$ & $19(37 \%)$ & $22(43 \%)$ & $10(20 \%)$ \\
\hline Missing & $2(1 \%)$ & $2(100 \%)$ & $0(0 \%)$ & $0(0 \%)$ & $0(0 \%)$ & $0(0 \%)$ & $0(0 \%)$ & $0(0 \%)$ \\
\hline Birth Weight & & & & & & & & \\
\hline$<2.5 \mathrm{~kg}$ & $68(49 \%)$ & $46(68 \%)$ & $17(25 \%)$ & $5(7 \%)$ & $122(70 \%)$ & $53(43 \%)$ & $43(35 \%)$ & $26(21 \%)$ \\
\hline$>2.5 \mathrm{~kg}$ & $70(50 \%)$ & $48(69 \%)$ & $11(16 \%)$ & $11(16 \%)$ & $53(30 \%)$ & $17(32 \%)$ & $25(47 \%)$ & $11(21 \%)$ \\
\hline
\end{tabular}




\begin{tabular}{|c|c|c|c|c|c|c|c|c|}
\hline Missing & $2(1 \%)$ & $2(100 \%)$ & $0(0 \%)$ & $0(0 \%)$ & $0(0 \%)$ & $0(0 \%)$ & $0(0 \%)$ & $0(0 \%)$ \\
\hline \multicolumn{9}{|l|}{ Gender } \\
\hline Male & $70(50 \%)$ & $44(63 \%)$ & $18(26 \%)$ & $8(11 \%)$ & $93(53 \%)$ & $41(44 \%)$ & $36(39 \%)$ & $16(17 \%)$ \\
\hline Female & $70(50 \%)$ & $52(74 \%)$ & $10(14 \%)$ & $8(11 \%)$ & $82(47 \%)$ & $29(35 \%)$ & $32(39 \%)$ & $21(26 \%)$ \\
\hline \multicolumn{9}{|c|}{ Deprivation Quintile } \\
\hline 1 & $1(1 \%)$ & $0(0 \%)$ & $1(100 \%)$ & $0(0 \%)$ & $3(2 \%)$ & $1(33 \%)$ & $2(67 \%)$ & $0(0 \%)$ \\
\hline 2 & $3(2 \%)$ & $0(0 \%)$ & $3(100 \%)$ & $0(0 \%)$ & $5(3 \%)$ & $0(0 \%)$ & $5(100 \%)$ & $0(0 \%)$ \\
\hline 3 & $11(8 \%)$ & $5(45 \%)$ & $2(18 \%)$ & $4(36 \%)$ & $21(12 \%)$ & $5(24 \%)$ & $12(57 \%)$ & 4 (19\%) \\
\hline 4 & $22(16 \%)$ & $16(73 \%)$ & $5(23 \%)$ & $1(5 \%)$ & $30(17 \%)$ & $8(27 \%)$ & $14(47 \%)$ & $8(27 \%)$ \\
\hline 5 & $99(71 \%)$ & $72(73 \%)$ & $16(16 \%)$ & $11(11 \%)$ & $108(62 \%)$ & $53(49 \%)$ & $32(30 \%)$ & 23 (21\%) \\
\hline Missing & $4(3 \%)$ & $3(75 \%)$ & $1(25 \%)$ & $0(0 \%)$ & $8(5 \%)$ & $3(38 \%)$ & $3(38 \%)$ & $2(25 \%)$ \\
\hline \multicolumn{9}{|c|}{ Consanguinity } \\
\hline Yes & $80(57 \%)$ & $75(94 \%)$ & $0(0 \%)$ & $5(6 \%)$ & $40(23 \%)$ & $38(95 \%)$ & $0(0 \%)$ & $2(5 \%)$ \\
\hline No & $49(35 \%)$ & $16(33 \%)$ & $26(53 \%)$ & $7(14 \%)$ & $123(70 \%)$ & $23(19 \%)$ & 66 (54\%) & $34(28 \%)$ \\
\hline Missing & $11(8 \%)$ & $5(45 \%)$ & $2(18 \%)$ & $4(36 \%)$ & $12(7 \%)$ & 9 (75\%) & $2(17 \%)$ & $1(8 \%)$ \\
\hline \multicolumn{9}{|c|}{ Maternal Age } \\
\hline$<20$ & $6(4 \%)$ & $4(67 \%)$ & $1(17 \%)$ & $1(17 \%)$ & $18(10 \%)$ & $1(6 \%)$ & $14(78 \%)$ & $3(17 \%)$ \\
\hline $20-34$ & $104(74 \%)$ & $80(77 \%)$ & $10(10 \%)$ & $14(13 \%)$ & $129(74 \%)$ & $57(44 \%)$ & 45 (35\%) & 27 (21\%) \\
\hline$>35$ & $20(14 \%)$ & $12(60 \%)$ & $7(35 \%)$ & $1(5 \%)$ & $27(15 \%)$ & $12(44 \%)$ & $8(30 \%)$ & $7(26 \%)$ \\
\hline Missing & $0(0 \%)$ & $0(0 \%)$ & $0(0 \%)$ & $0(0 \%)$ & $1(1 \%)$ & $0(0 \%)$ & $1(100 \%)$ & $0(0 \%)$ \\
\hline \multicolumn{9}{|c|}{ Smoking in Pregnancy } \\
\hline Yes & $10(7 \%)$ & $2(20 \%)$ & $5(50 \%)$ & $3(30 \%)$ & $41(23 \%)$ & $0(0 \%)$ & $26(63 \%)$ & $15(37 \%)$ \\
\hline No & $123(88 \%)$ & $90(73 \%)$ & $21(17 \%)$ & $12(10 \%)$ & $117(67 \%)$ & $67(57 \%)$ & $29(25 \%)$ & $21(18 \%)$ \\
\hline Missing & $7(5 \%)$ & $4(57 \%)$ & $2(29 \%)$ & $1(14 \%)$ & $17(10 \%)$ & $3(18 \%)$ & $13(76 \%)$ & $1(6 \%)$ \\
\hline \multicolumn{9}{|c|}{ Maternal IIIness } \\
\hline Yes & $12(9 \%)$ & $8(67 \%)$ & $4(33 \%)$ & $0(0 \%)$ & $23(13 \%)$ & $10(43 \%)$ & $10(43 \%)$ & $3(13 \%)$ \\
\hline No & $115(82 \%)$ & $81(70 \%)$ & $21(18 \%)$ & $13(11 \%)$ & $129(74 \%)$ & $55(43 \%)$ & $45(35 \%)$ & 29 (22\%) \\
\hline Missing & $13(9 \%)$ & 7 (54\%) & $3(23 \%)$ & $3(23 \%)$ & $23(13 \%)$ & $5(22 \%)$ & $13(57 \%)$ & $5(22 \%)$ \\
\hline
\end{tabular}

Table 4: Univariate and Multivariate Odds Ratios for the risk of death related to congenital anomaly compared to other causes.

\begin{tabular}{|c|c|c|c|c|}
\hline \multirow[b]{2}{*}{ Characteristic } & \multicolumn{2}{|l|}{ Univariate } & \multicolumn{2}{|l|}{ Multivariate } \\
\hline & OR (95\% Cl) & p-value & OR & p-value \\
\hline \multicolumn{5}{|l|}{ Ethnicity ( $n=315)$} \\
\hline Pakistani & $3.33(1.95-5.70)$ & $<0.001$ & $1.13(0.44-2.91)$ & 0.808 \\
\hline White British & 1.00 & - & 1.00 & - \\
\hline Other & $1.05(0.50-2.19)$ & 0.74 & $0.54(0.19-1.51)$ & 0.241 \\
\hline \multicolumn{5}{|l|}{ Age at death $(n=315)$} \\
\hline 0 & 1.00 & - & 1.00 & - \\
\hline $1-28$ & $0.92(0.51-1.66)$ & 0.792 & $1.12(0.47-2.63)$ & 0.241 \\
\hline$>28$ & $1.25(0.68-2.27)$ & 0.446 & $0.77(0.33-1.78)$ & 0.538 \\
\hline \multicolumn{5}{|l|}{ Gestation ( $n=315)$} \\
\hline Preterm & 1.00 & - & 1.00 & - \\
\hline Term & $3.76(2.35-6.01)$ & $<0.001$ & $3.18(1.34-7.54)$ & 0.008 \\
\hline \multicolumn{5}{|l|}{ Birth Weight $(n=313)$} \\
\hline$<2.5 \mathrm{~kg}$ & 1.00 & - & 1.00 & - \\
\hline$>2.5 \mathrm{~kg}$ & $2.37(1.49-3.77)$ & $<0.001$ & $0.96(0.41-2.26)$ & 0.925 \\
\hline \multicolumn{5}{|l|}{ Gender $(n=315)$} \\
\hline Male & 1.00 & - & 1.00 & - \\
\hline Female & $1.13(0.73-1.80)$ & 0.579 & $1.29(0.72-2.34)$ & 0.394 \\
\hline Consanguinity $(n=292)$ & & & & \\
\hline
\end{tabular}




\begin{tabular}{|l|l|l|l|l|}
\hline No & 1.00 & - & 1.00 & - \\
\hline Yes & $5.02(3.03-8.31)$ & $<0.001$ & $3.28(1.48-7.29)$ & 0.004 \\
\hline Deprivation Q (n=304) & & & & \\
\hline 1 & $0.64(0.06-6.86)$ & 0.709 & $1.19(0.04-32.20)$ & 0.919 \\
\hline 2 & $1.15(0.23-5.71)$ & 0.868 & $0.80(0.10-6.58)$ & 0.838 \\
\hline 3 & 1.00 & - & 1.00 & - \\
\hline 4 & $1.4(0.56-3.49)$ & 0.470 & $1.52(0.45-5.07)$ & 0.499 \\
\hline 5 & $1.77(0.81-3.85)$ & 0.152 & $1.31(0.46-3.73)$ & 0.916 \\
\hline Maternal Age (n=315) & & & & \\
\hline$<20$ & $0.38(0.14-0.98)$ & 0.046 & $0.61(0.16-2.36)$ & 0.475 \\
\hline $20-35$ & 1.00 & - & 1.00 & - \\
\hline$>35$ & $0.81(0.43-1.51)$ & 0.506 & $0.96(0.42-2.19)$ & 0.916 \\
\hline $\begin{array}{l}\text { Smoking in Pregnancy } \\
\text { (n=292) }\end{array}$ & & & & \\
\hline No & 1.00 & - & 1.00 & - \\
\hline Yes & $0.23(0.11-0.48)$ & $<0.001$ & $0.54(0.19-1.51)$ & 0.243 \\
\hline $\begin{array}{l}\text { Maternal IIIness } \\
\text { (n=279) }\end{array}$ & & & & \\
\hline No & 1.00 & - & 1.00 & - \\
\hline Yes & $0.59(0.28-1.28)$ & 0.157 & $0.66(0.26-1.68)$ & 0.382 \\
\hline
\end{tabular}

\section{What is known already}

Infant mortality varies by ethnicity.

Causes of infant mortality vary by ethnicity.

Congenital anomalies are associated with consanguinity and maternal age in an ethnically mixed population.

\section{What does this study add?}

The excess mortality from congenital anomalies in Pakistani infants may be mediated by consanguinity rather than other factors.

CDOPs are a valuable source of information not only for identifying modifiable factors in individual cases, but also for describing larger population trends and providing generalisable learning for healthcare planning. 


\section{Funding Statement:}

This research received no specific grant from any funding agency in the public, commercial or not-for-profit sectors.

\section{Authorship Statement:}

CF and SO had the initial idea for the study, an original version of which formed the dissertation for CF's MSc in Child Health (for which SO and EP were supervisors). All three authors were involved in the study design. CF carried out the data collection. EP advised regarding statistics and performed the Stata analysis. CF wrote a draft version of this work. All three authors were subsequently involved in revisions and gave final approval of the version submitted for publication and agree to be accountable for all aspects of this work. 


\section{References:}

1. Office for National Statistics. Statistical bulletin: Pregnancy and ethnic factors influencing births and infant mortality: 2013. Published October 2015

2. Gray R, Oakley L, Kurinczuk J et al. Inequalities in infant mortality project briefing paper 3. Towards an understanding of variations in infant mortality rates between different ethnic groups. Oxford: National Perinatal Epidemiology Unit, 2009.

3. Kurinczuk J, Boyd P. Oakley L et al.Inequalities in infant mortality project briefing paper 4 . The contribution of congenital anomalies to infant mortality. Oxford: National Perinatal Epidemiology Unit, 2010.

4. Chimat. Data Atlas for Infant Mortality in England and Wales 2017 [Available from: http://chimat.org.uk.

5. Bradford Joint Strategic Needs Assessment. Infant Mortality in Bradford. 2014

6. Schwarz K, Yeung S, Symons N, et al. Survey of school children with visual impairment in Bradford. Eye (Lond) 2002;16(5):530-4. doi: 10.1038/sj.eye.6700059 [published Online First: 2002/08/24]

7. Devereux G, Stellitano L, Verity CM, et al. Variations in neurodegenerative disease across the UK: findings from the national study of Progressive Intellectual and Neurological Deterioration (PIND). Arch Dis Child 2004;89(1):8-12. [published Online First: 2004/01/08]

8. Corry PC. Intellectual disability and cerebral palsy in a UK community. Community Genet 2002;5(3):201-4. doi: 66337 [published Online First: 2004/02/13]

9. Sheridan E, Wright J, Small N, et al. Risk factors for congenital anomaly in a multiethnic birth cohort: an analysis of the Born in Bradford study. Lancet 2013;382(9901):1350-9. doi: 10.1016/S0140-6736(13)61132-0 [published Online First: 2013/07/09]

10. HM Government. Working Together to Safeguard Children. In: Education Df, ed. London: The Stationary Office, 2006.

11. Wright J, Small N, Raynor P, et al. Cohort Profile: the Born in Bradford multi-ethnic family cohort study. Int J Epidemiol 2013;42(4):978-91. doi: 10.1093/ije/dys112 [published Online First: 2012/10/16]

12. McHugh ML. Interrater reliability: the kappa statistic. Biochem Med (Zagreb) 2012;22(3):276-82. [published Online First: 2012/10/25]

13. Froen JF, Pinar H, Flenady V, et al. Causes of death and associated conditions (Codac): a utilitarian approach to the classification of perinatal deaths. BMC Pregnancy Childbirth 2009;9:22. doi: 10.1186/1471-2393-9-22 [published Online First: 2009/06/12]

14. Stata Statistical Sofrware: Release 14 [program]. College Station, TX: StataCorpLP, 2015.

15. Fairley L, Cabieses B, Small N, et al. Using latent class analysis to develop a model of the relationship between socioeconomic position and ethnicity: cross-sectional analyses from a multi-ethnic birth cohort study. BMC Public Health 2014;14:835. doi: 10.1186/1471-2458-14835 [published Online First: 2014/08/15]

16. Oakley L, Maconochie N, Doyle $P$, et al. Multivariate analysis of infant death in England and Wales in 2005-06, with focus on socio-economic status and deprivation. Health Stat $Q$ 2009(42):22-39. [published Online First: 2009/07/01]

17. Collingwood Bakeo A. Investigating variations in infant mortality in England and Wales by mother's country of birth, 1983-2001. Paediatr Perinat Epidemiol 2006;20(2):127-39. doi: 10.1111/j.1365-3016.2006.00708.x [published Online First: 2006/02/10]

18. Bhopal RS, Petherick ES, Wright J, et al. Potential social, economic and general health benefits of consanguineous marriage: results from the Born in Bradford cohort study. Eur J Public Health 2014;24(5):862-9. doi: 10.1093/eurpub/ckt166 [published Online First: 2013/11/12]

19. Hamamy H, Antonarakis SE, Cavalli-Sforza LL, et al. Consanguineous marriages, pearls and perils: Geneva International Consanguinity Workshop Report. Genet Med 2011;13(9):841-7. doi: 10.1097/GIM.0b013e318217477f [published Online First: 2011/05/11] 
20. Alhamdan NA, Almazrou YY, Alswaidi FM, et al. Premarital screening for thalassemia and sickle cell disease in Saudi Arabia. Genet Med 2007;9(6):372-7. doi:

10.1097GIM.0b013e318065a9e8 [published Online First: 2007/06/19]

21. Bradford Metropolitan District. Every Baby Matters.

22. Raising Awareness of Genetics Among Culturally Diverse Communities; 2012; Leeds.

23. Project BCG. Bradford Community Genetics Project Report: Progress Report, Challenges and Achievements. 2012

24. Neasham D, Dolk $H$, Vrijheid $M$, et al. Stillbirth and neonatal mortality due to congenital anomalies: temporal trends and variation by small area deprivation scores in England and Wales, 1986-96. Paediatr Perinat Epidemiol 2001;15(4):364-73. [published Online First: 2001/11/13]

25. Smith LK, Manktelow BN, Draper ES, et al. Nature of socioeconomic inequalities in neonatal mortality: population based study. BMJ 2010;341:c6654. doi: 10.1136/bmj.c6654 [published Online First: 2010/12/04] 